\title{
Study on the Optimization Model of Bus Transit Site Distribution between Metro and Bus Connection
}

\author{
Chen Ningning \\ Department of Technology, Xi'an International University, Shaanxi, Xi'an, 710077, China
}

Keywords: subway, bus, connection, model optimization

\begin{abstract}
In this paper, based on the optimization of the shortest transit distance between Xi'an subway and bus station, a simplified model for the distribution of the optimal transit site is established. At the same time, the influence of the bus stop on the intersection is taken as the constraint condition, and the location of the bus station is the shortest when the transit distance is the shortest.
\end{abstract}

\section{Introduction}

In recent years, the construction of Xi'an Rail Transit is surging exuberantly. In 2011, the first metro line was open for trial operation, then, Xi'an became the first city with metro in northwest China. Especially, it has obtained considerable progress in various construction works of Xi'an Metro. In combination with future planning, the quantity of metro lines in Xi'an will reach 15 with a total length of $652 \mathrm{~km}$ and daily passenger times of 11.88 million, accounting for $46 \%$ of overall travel rate of public transport. The constant improvement of Xi'an Rail Transit makes the public transport structure of Xi'an in the future developed into a favorable layout with rail transit as the main framework and conventional bus transit as the supplement. In the areas without rail transit, bus is the major mean of transportation in urban traffic; but in these areas with the coverage of rail transit, metro will become the main connection mode to distribute passenger flow. Because door-to-door transport can't be realized in rail transit, in order to maximize its backbone effectiveness, we must achieve seamless connection with bus, thus realizing zero-distance transfer of passengers ${ }^{[1,7,9]}$. In this paper, based on the existing metro stations, it makes microscopic adjustment for the distribution of bus stops, and sets the shortest transfer distance of connecting the metro and bus as the objective function to create the optimization model for the layout of bus stops. This paper mainly takes North Zhangba Road Station of Metro Line 3 as the example to carry out investigation and analysis as well as model verification for solution, thus obtaining the detailed optimization scheme.

\section{Problem Analysis}

Xi'an Metro Line 3 Project had the planning completed in 2011 and the construction commenced in 2012. It is predicted to be open to traffic by the end of 2016. Metro Line 3 stretches from Yuhuazhai to Qinglong Temple along Keji Road, then turns towards northeast and connects Xi'an International Trade \& Logistic Park. It is the backbone line in rail network planning in Xi'an and also the only line with viaduct among the recent constructed metros in Xi'an, with a total distance of $39.9 \mathrm{~km}$ and maximum operating speed of $80 \mathrm{~km} / \mathrm{h}$ via 26 stations, including 11 transfer stations. Later, it will realize the transfer with Metro 1, 2, 4, 5, 6, 7, 8 and 14. Currently, 6 transfer stations have been open to traffic. See details in Figure1. 


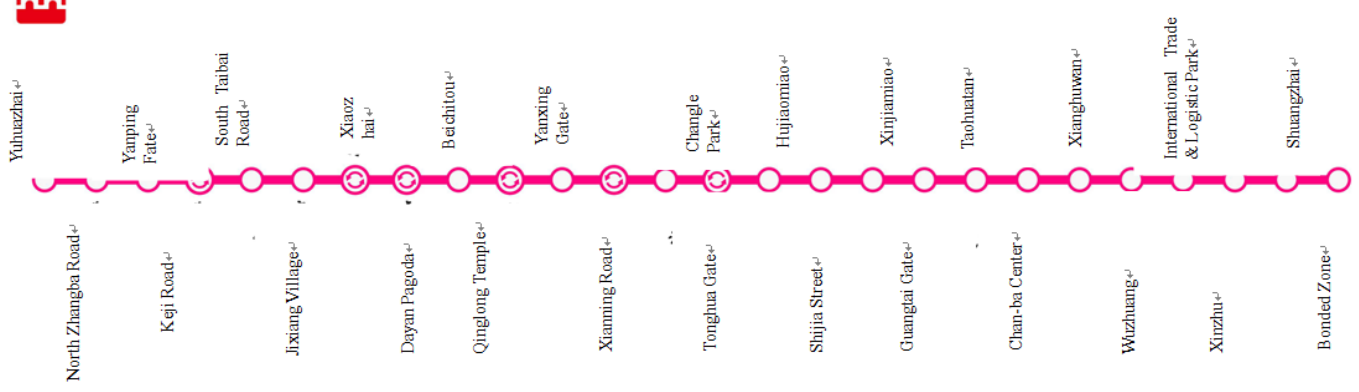

Figure 1: Metro Line 3 Site Distribution

North Zhangba Road Station of Metro Line 3 is located at the east of the intersection of Fuyu Road and North Zhangba Road, stretching from east to west along Keji Road. Vanguard Supermarket and resident communities are on the northeast corner of the intersection, and city shops, Urban Impression, Miro \& Blue Mountain and other commercial \& residential communities are on the southeast. Current width of Keji Road is $40 \mathrm{~m}$ and the width within the boundary line of North Zhangba Road is $60 \mathrm{~m}$, with heavier traffic. The surroundings are planned as residential land. Bus traffic at the intersection of North Zhangba Road Station accounts for $4.12 \%$ of vehicle flow quantity and 16 bus lines are set here in total. The detailed bus line profile is shown as Table 1 .

Table 1: Bus Lines Profile

\begin{tabular}{|c|c|c|}
\hline Line & Origin station and Terminal & Departure Frequency \\
\hline 711 & $\begin{array}{c}\text { Xi'an Vocational \& Technical College - South of } \\
\text { Beichen Interchange }\end{array}$ & $7 \mathrm{~min} / \mathrm{bus}$ \\
\hline 405 & South Gate - West of Doumen & $6 \mathrm{~min} / \mathrm{bus}$ \\
\hline 201 & Xi'an Railway Station - Xixinzhuang & $7 \mathrm{~min} / \mathrm{bus}$ \\
\hline 225 & Jixiang Village - North Hancheng Road & $5 \mathrm{~min} /$ bus \\
\hline 312 & Xi'an Crane Factory - Dynasty Star City & $4 \mathrm{~min} / \mathrm{bus}$ \\
\hline 300 & $\begin{array}{c}\text { North Campus of Xi'an International University - } \\
\text { Xingfu Road }\end{array}$ & $4 \mathrm{~min} / \mathrm{bus}$ \\
\hline 202 & Shaanxi Library - Xixinzhuang & $4 \mathrm{~min} / \mathrm{bus}$ \\
\hline 800 & Xixinzhuang - No.8 Bus Company & $6 \mathrm{~min} / \mathrm{bus}$ \\
\hline 253 & $\begin{array}{c}\text { Dazhai Road (West) - Northwest Academy of } \\
\text { Martial Arts }\end{array}$ & $7 \mathrm{~min} / \mathrm{bus}$ \\
\hline 308 & $\begin{array}{l}\text { North Campus of Xi'an International University - } \\
\text { Weishi Street }\end{array}$ & $8 \mathrm{~min} / \mathrm{bus}$ \\
\hline Travel No.7 & $\begin{array}{c}\text { Xi’an Vocational \& Technical College - Xi’an } \\
\text { Railway Station }\end{array}$ & $15 \mathrm{~min} / \mathrm{bus}$ \\
\hline 604 & $\begin{array}{l}\text { North Campus of Xi'an International University - } \\
\text { East Gate }\end{array}$ & 8min/bus \\
\hline 725 & Tongfangxiang Community - Keji Road (West) & $10 \mathrm{~min} / \mathrm{bus}$ \\
\hline 40 & $\begin{array}{c}\text { North Campus of Xi'an International University - } \\
\text { Xi'an Railway Station }\end{array}$ & $5 \mathrm{~min} /$ bus \\
\hline 902 & $\begin{array}{c}\text { Xi'an Science \& Technology Training College - } \\
\text { Shanglinyuan } 1^{\text {st }} \text { Road }\end{array}$ & $15 \mathrm{~min} / \mathrm{bus}$ \\
\hline 908 & $\begin{array}{c}\text { Xi'an Cheng Nan Coach Station - Fuyuan } 5^{\text {th }} \text { Road } \\
\text { (South) }\end{array}$ & $15 \mathrm{~min} / \mathrm{bus}$ \\
\hline
\end{tabular}

Locations of Bus Stops set in various sections near North Zhangba Road Station are shown as Figure 2. It can be seen from the figure of current station distribution, the buses passing Keji Road (West) are distributed in Keji Road, Fuyu Road and North Zhangba Road. Nine lines of 711, 405, 201, 225, 312, 300, 202, 800, 253 stop are at the exit direction of the intersection in the North of 
North Zhangba Road, and six bus lines of 308, 40, 604, 902, 725, and Travel No.7 stop at the intersection direction in the north of Fuyu Road. After the completion, Metro Line 3 will work to share the passenger flow at the west and east direction, while for the passengers transferring from north and south to east and west at the intersection, it can also meet their need for transfer.

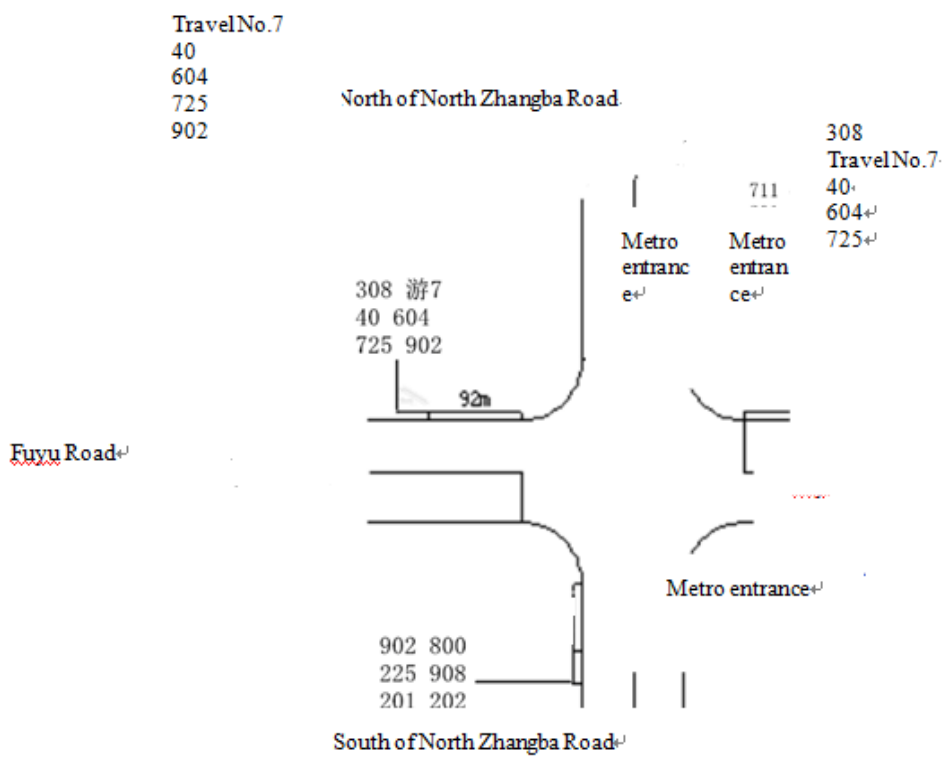

Figure 2: The Bus Distribution Map of the North Zhangba Road

Bus lines and bus stops are featured by the advantages of flexible change and strong traffic capacity, hence, bus is the best connection mode of rail transit. Through the targeted analysis on the results of field investigation for North Zhangba Road Station of Metro Line 3, it is found the location selection of bus stops mainly depends on the influence factors below ${ }^{[11-13,15,16]}$

(1) Layout of land use surrounding the bus stops and Locations of bus stops

Generally, as for land layout, it mainly includes residence, public facilities, industry, road \& square and other land use ${ }^{[2]}$. There are usually more residence areas near the bus stops and large resident travel volume, hence, the resident travel volume within the service scope of bus stops and the probability of travel mode selected by travelers are closely related to land layout. Secondly, after the construction, completion and putting into operation, Metro Line 3 will be a new occurrence source and attraction source for travel in North Zhangba Road, hence, in terms of selection of bus stops, it shall take the demand for transfer and travel in metro stations into consideration. Due that North Zhangba Road Station is at the intersection, being the node gathering and distributing the passenger flow in various directions, if the bus stops are closer to the intersection, more passengers near the intersection will be attracted for travel and transfer. Meanwhile, it also facilitates for the gathering and distribution of passengers.

(2) Travel distance of passengers transferring to bus stops

For transfer passengers, shortest distance, fastest travel time and lowest cost are the main consideration factors in the selection of transfer of bus. Hence, in order to get the lowest total cost for passengers transferring to bus stops, one most fundamental thing is to reduce the walking distance of passengers transferring to bus stops, which can both enhance the attractiveness of public transport and the probability of passengers selecting conventional bus transit. If the distance is longer, passengers may give up the travel by bus.

(3) Mutual affect from synchronous drawing up at bus stops

Through field investigation, it indicates that there are more buses near North Zhangba Road and stopping at the same station, see details in Figure 2. According to Highway Capacity Manual of the U.S., service level of stations can quantize cost weighting coefficient, the lower the service level, the greater the cost produced from public traffic system. Therefore, when multiple buses entering 
one station at the same time, excessive buses can directly lead to excessive passenger flow and the decrease of service level of public transport. When selecting the locations of bus stops, it is needed to consider the mutual affect of buses stopping at the same station to avoid crowding, prolonged stopping and overlong queuing, which may further lead to a decrease of travel level, thus the passengers may transfer to other means of transportation.

\section{Optimization Mode for Site Selection of Bus Stations Connecting Metro and Conventional Bus Transit}

After the determination of metro site, relevant bus lines around the site can play a role in gathering and distributing passenger flow for the site. As per the distribution and arrangement for transfer station in North Zhangba Road of Metro Line 3, locations for conventional bus stops around North Zhangba Road Station are optimized and arranged reasonably after investigating and analyzing the bus line distribution in this station as well as travel demand of passengers. Meanwhile, it is required bus stops shall be set at a nearer distance from the metro station as possible. In this paper, the site selection for bus stops and the arrangement for conventional bus stops around the metro stations at the intersection of Keji Road (West) are optimized. It takes the shortest transfer distance between metro and bus stops as objective function and the minimum impact factor of bus stops for the intersection as the constraint condition to make the models ${ }^{[5]}$, from which, we can further obtain the optimized arrangement location for the conventional bus stops around North Zhangba Road Metro Station, which shortens the distance of passengers traveling between metro and bus to the greatest extent ${ }^{[18]}$.

A simplified model with the distribution of optimal stations is established with the shortest transfer distance between metro and bus as the optimization target. North Zhangba Road Metro Station is taken as the study objective, which is the second station of Metro Line 3 from west to east located below Keji Road with two entrances. In line with the investigation and analysis on bus line distribution around North Zhangba Road Metro Station, the layout is obtained for bus stops near North Zhangba Road Station. Relative position of the two is shown in Figure 3.

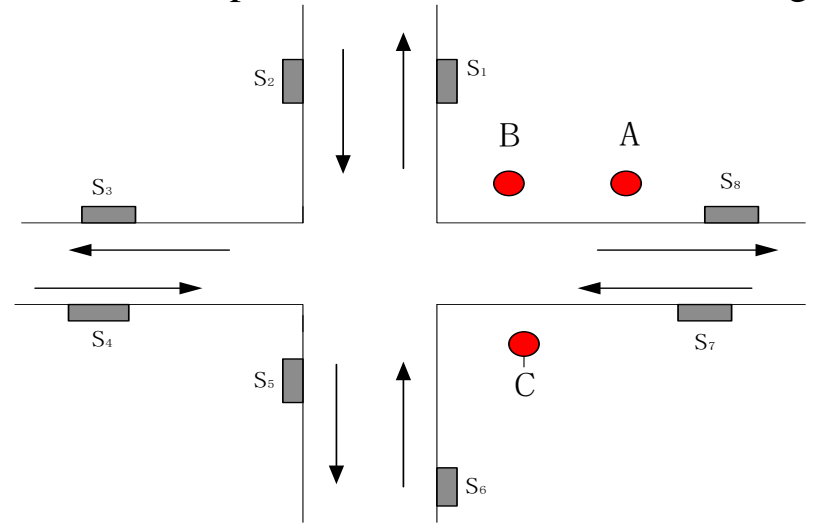

Figure 3: The Plane Relation Map of the Eight North Road Station

During the process of modeling, the assumptions and parameters below are set in order to simplify the computing:

(1) Ignore the time delay assuming that the pedestrians cross the road with diversified mode;

(2) Do passengers need to cross the street while transferring to the entrance of metro stations from different areas? Assuming the distance increased due to crossing the street once is $500 \mathrm{~m}$, and the times to cross the street is recorded as $c$, if the value is 0 , it means passengers don't have to cross the street; 1 means passengers need to cross the street once to arrive at the transfer station, 2 means twice.

(3) Each bus line is relatively independent to the bus stops

According to the known condition in investigation, three entrances of North Zhangba Road Metro Station are set as $\mathrm{A}\left(x_{a}, y_{a}\right), \mathrm{B}\left(x_{b}, y_{b}\right), \mathrm{C}\left(x_{c}, y_{c}\right)$; coordinates of the bus stops around North 
Zhangba Road Station are $S_{1}\left(x_{1}, y_{1}\right), S_{2}\left(x_{2}, y_{2}\right), S_{3}\left(x_{3}, y_{3}\right), S_{4}\left(x_{4}, y_{4}\right), S_{5}\left(x_{5}, y_{5}\right), S_{6}$ $\left(x_{6}, y_{6}\right), S_{7}\left(x_{7}, y_{7}\right), S_{8}\left(x_{8}, y_{8}\right)$. length of the passageway at three entrances of North Zhangba Metro Station is $s_{1}, s_{2}, s_{3}$, then it get the target function model of linear planning with the shortest transfer distance, which is expressed in details as below:

$$
\operatorname{Min} D=D_{S_{1} B}+D_{S_{2} B}+D_{S_{3} B}+D_{S_{8} A}+D_{S_{4} C}+D_{S_{5} C}+D_{S_{6} C}+D_{S_{7} C}
$$

Wherein: $D_{S_{1} B}$-is the shortest distance from bus stop $S_{1}\left(x_{1}, y_{1}\right)$ to Metro Entrance B $\left(x_{b}, y_{b}\right)$, including the length of the passageway at the Metro Entrance B;

$D_{S_{2} B}$ is the shortest distance between Bus Station $S_{2}\left(x_{2}, y_{2}\right)$ and the Metro Entrance B $\left(x_{b}, y_{b}\right)$, including the length of the passageway at the Metro Entrance B and the distance crossing the street once;

Similarly, $D_{S_{3} B}, D_{S_{8} A}, D_{S_{4} C}, D_{S_{5} C}, D_{S_{6} C}, D_{S_{7} C}$ are the shortest distance of other bus stops to the three metro entrances.

When optimizing the distribution of bus stops, set the minimum affect of bus stop on intersection as the constraint condition. The constraint condition for stop location $\mathrm{L}$ at entrance is that it should be greater than the maximum queuing length $\mathrm{D}$ at the time of red light.

$$
\mathrm{L} \geq \mathrm{D}
$$

According to relevant data collected from field investigation at North Zhangba Road, assign values for relevant parameters of the model. The specific parameters in the known conditions are as follows: (1) Set the origin of coordinates at the center point ${ }^{[6,14]}$ of the intersection of Keji Road (West) for the solutions of the model.

(2) Coordinates for the three entrances of North Zhangba Road Metro Station - A, B, and C respectively are $\mathrm{A}\left(x_{a}, y_{a}\right), \mathrm{B}\left(x_{b}, y_{b}\right), \mathrm{C}\left(x_{c}, y_{c}\right)$.

(3) When making out the solutions for model, take the frequency of passengers' crossing the street as the metro entrance which is the minimum frequency in proximity transfer to judge the frequency of crossing the street $\mathrm{C}$;

(4) Through field research, we can get the value of the length of the passageways $s_{1}, s_{2}, s_{3}$ of the three entrances in North Zhangba Road Metro Station.

Substitute the parameters obtained above into the model for solution to get the shortest distance when transferring from metro to bus and the coordinates $S_{1} \sim S_{7}$ of bus stops at each direction which exert minimum affect on the intersection.

\section{Conclusion}

For enhancing the travel efficiency of the public and reducing space and time consumption, we must take full advantage of various public transport resources of the city, therefore, it appear to be particularly important to study and carry out efficient connection and optimization between metro and bus. This paper introduces the status of Xi'an Metro Line 3 and current status of conventional public traffic, from which, we get to know the necessity of the connection and optimization for the transfer of the both. Based on the microcosmic adjustment of the distribution of conventional bus stop according to the current metro station, take the shortest transfer distance between metro and conventional public traffic as the objective function and the minimum impact of bus stops on intersection as the constraint condition to build the linear programming model. Through building the model and solving the problems, it can get the location of each bus stop around the metro station with optimal distribution, which provides us the theoretical method for efficient connection of metro and conventional public traffic, and lays a foundation for creating a mutual harmonious integrated passenger transport system with diversified means of transportation in the future. 


\section{References}

[1] Zhang Yi. Optimization and Application of Conventional Public Transit Network under Rail Traffic Impact [D]. Chengdu: Southwest Jiao Tong University, 2014 (in Chinese)

[2] Wang Lin, Chen Dapeng. The analysis and fuzzy evaluation of the site selection of the bus station[J]. Traffic Science and Technology and Economy, 2009(6):47-49 (in Chinese)

[3] Wei Ha. Research on Key Problems of Rail Transit and Bus Transit Optimization[D]. Xi'an: Chang'an University, 2014 (in Chinese)

[4] Tian Chunchun. Research on Optimal Design of Conventional Bus Stop[D]. Changsha: Central South University, 2009 (in Chinese)

[5] Zhan Shuo. Research on Connection Transfer Between Urban Rail Transit and Conventional Bus Stops on the Ground[D]. Xi'an: Xi'an University of Architecture and Technology, 2011 (in Chinese)

[6] Sun Fansong, Zhang Kairan, Wang Ruocheng. Transfer Model Between Rail Transit and Regular Bus at Intersection[J]. Journal of Transportation Engineering and Information, 2015 (9): 76-80 (in Chinese)

[7] Ling Tingting, He Rui, He Shiwei. Bottleneck Identification Method of Passenger Distributing Facilities in Comprehensive Passenger Terminal [J]. Journal of Transportation Engineering and Information, 2014(04) (in Chinese)

[8] Genetic Algorithm Approach for Transit Route Planning and Design[J]. Steven Chien,Zhaowei Yang,Edwin Hou. Journal of Transportation Engineering. 2001 (3)

[9] Zhao Xiaoju. Research on Coordinated Transfer Between Urban Rail Transit and Regular Bus [D]. Changsha: Changsha University of Science and Technology, 2006(in Chinese)

[10] Three Fastest Shortest Path Algorithms on Real Road Networks: Data Structures and Procedures [J]. FB Zhan . ResearchGate . 1996

[11] Zhao Yue, Du Wen. Study on Effect of Bus stop on Capacity of Road Section[J]. Journal of Highway and Transportation Research and Development, 2007, 24(8): 136-139(in Chinese)

[12] $\mathrm{Hu}$ Junhui, Yang Li, Kong Lingjiang, et a1. Urban Mixed Traffic Flow Considering the Influence by Origin - destination of Public Transportation $\mathrm{f}[\mathrm{J}]$. Journal of Transportation Systems Engineering and Information Technology, 201l, 11(1): 102-107(in Chinese)

[13] Ma Changxi, Ma Chaoqun. Traffic Impact Assess-ment[M]. Beijing: China Machine Press,2014(in Chinese)

[14] Li Yun, Huang Zhengdong. Construction of Multilevel Bus Site Model Based on UML[J]. Journal of Transportation Engineering and Information, 2006(06):13-17(in Chinese)

[15] Qiu Yang. Research on Increasing Parking Capacity of Bus Stop[D]. Wuhan: Huazhong University of Science and Technology, 2007 (in Chinese)

[16] Wang Jianglan. Analysis on Affecting Factors of Delay on Regular Bus Stop[D]. Xi'an: Chang'an University, 2014(in Chinese)

[17] Jiang Fan. Study on the Connection Between Urban Track and other Traffic Modes[J]. Journal of Northern Jiaotong University, 2011 (4): 108 - 110. (in Chinese)

[18] An Efficient Implementation of Shortest Path Algorithm Based on Dijkstra Algorithm[J]. Y Yue. Journal of Wuhan Technical University of Surveying \& Mapping.1999 